\title{
LEITURA SOBRE O NEGRO NA CIDADE DE GOIÁS A PARTIR DA CAPOEIRA ANGOLA
}

\author{
READING ABOUT THE NEGRO IN THE CITY OF GOIÁS FROM \\ CAPOEIRA ANGOLA
}

\section{LECTURA ACERCA DE LOS NEGROS EN LA CIUDAD DE GOIÁS POR LA CAPOEIRA ANGOLA}

\author{
Rosemberg Ferracini - Universidade de São Paulo - São Paulo - São Paulo - Brasil \\ rosemberggeo@yahoo.com.br \\ Carlos Eduardo Santos Maia - Universidade Federal de Juiz de Fora - Juiz de Fora - Minas Gerais - Brasil \\ carlmaia@uol.com.br
}

\section{Resumo}

Neste trabalho dedicamos nossa atenção à investigação da territorialidade e da identidade negras como dilemáticas aos integrantes do grupo de capoeiristas angoleiros na Cidade de Goiás, discutindo como estes grupos se (re)constituíram a partir da inserção de seus membros no projeto "Anunciando a Consciência Negra com os Meninos de Angola". Assim, investigamos o significado desta arte negra para as pessoas que participam e se engajam no projeto, bem como alguns rituais e práticas espaciais que orientam suas territorialidades nessa cidade. Nosso objetivo na pesquisa foi compreender o projeto do grupo, que é direcionado para jovens, adultos e crianças, assim como a proposta de resgate da ancestralidade e religiosidade negras, bases da territorialidade e identidade como "capoeiristas angoleiros". Estas intenções nos levaram, paralelamente, a interpretar os próprios ideários relacionados ao modo de ser do capoeirista.

Palavras-chave: territorialidade, identidade, religiosidade, capoeira angola.

\section{Abstract}

In this paper, we are interested in the investigation of territoriality and black identity disruptions seen among the members of a capoeira group called Angoleiros in the City of Goiás, discussing how they have been re-founded by the insertion of its members in the project "Advertising with the Black Consciousness Children of Angola". Thus, we have searched the significance of this black art to people who take part and are engaged in the project, as well as some rituals and practices that guide their spatial territoriality in this city. Our goal in this research was to apprehend the nature of the group project drafting, which is directed to youth, adults and children together with the experience of the proposed redemption of black ancestry and religion, bases of territoriality and identity for "Capoeiristas Angoleiros". Those remarks led us, in parallel, to interpret their own ideologies related to the concept of how to be a "capoeira".

Key words: territoriality, identity, religion, capoeira Angola.

\section{Resumen}

A través de este trabajo buscamos investigar la territorialidad y los dilemas asociados a la identidad negra en los integrantes del grupo de capoeiristas angoleiros de la ciudad de Goiás. Buscamos discutir cómo estos grupos se (re)constituyeron a partir de la inserción de sus miembros en el proyecto "Anunciando a Consciência Negra com os Meninos de Angola". De esta manera, investigamos tanto la significación de este arte negro para las personas que participan y se involucran en el proyecto, como algunos rituales y prácticas espaciales que guían sus territorialidades en esta ciudad. Nuestro objetivo en esta investigación fue comprender la naturaleza de la elaboración de proyecto del grupo orientado a jóvenes, adultos y niños, así como la experiencia de la propuesta de rescatar la ancestralidad y religiosidad negra, bases de la terri- 
torialidad y la identidad en tanto capoeiristas angoleiros. Estas intenciones nos han llevado, en paralelo, a interpretar sus propios idearios relacionados con el modo de ser capoeirista

Palabras clave: territorialidad, identidad, religiosidad y capoeira Angola.

Breve resgate histórico

Angola, capoeira, mãe

Mandinga de escravo em ânsia de liberdade, seu princípio não tem método, seu fim é inconcebível ao mais sábio dos mestres.

(Mestre Pastinha)

Embora o jogo de capoeira já tivesse ocorrido nos terreiros desde os tempos coloniais, em especial a espacialidade e a temporalidade da capoeira angola ${ }^{1}$ foram definidos inicialmente em Salvador, Bahia, quando, nos anos de 1940, Mestre Pastinha ${ }^{2}$ fundou seu Centro de Capoeira Angola, no Largo do Pelourinho (Reis, 2000, p. 111). Em 1971, na cidade de São Paulo, surgiu o grupo Capitães d'Areia, nome inspirado na obra de Jorge Amado. Para Reis, a formação desse grupo relaciona-se com a migração de baianos e constituiu-se "como um sinal de distinção que afirmava sua identidade de migrantes pobres oprimidos" (p. 141), em referência à história dos negros no país. Foi assim que em São Paulo, no ano seguinte, fundou-se a primeira federação de capoeira, nos fins dos anos 70. Ainda segundo o autor, foi criado em 1982 o Grupo de Capoeira Angola Pelourinho (GECAP), cujo propósito básico era "preservar popularmente o que ainda restava da autenticidade das artes negras" (p. 155) com raízes africanas no Brasil, coincidindo com o momento em que a capoeira angola ganhava maior importância. Por trás deste fato está a figura de Pedro de Moraes Trindade, mais conhecido como Mestre Moraes, ${ }^{3}$ que foi o grande responsável na reestruturação de alguns preceitos da manifestação negra relacionados à religiosidade e reafricanização, que estão intrincados na corporeidade, cânticos, toques e respeito ao outro e à cultura negra.

Em algumas falas de Pastinha, assim como em outros escritos sobre a capoeira, corre a versão de que esta, na África, recebia o nome de "dança de zebra”, também conhecida como N' Golo, sendo praticada como rito de passagem ligado à iniciação feminina, marcando a transição da adolescência para a idade adulta. Mas neste ritual quem efetivamente jogava capoeira eram os homens e não as mulheres. Eram os homens que lutavam como zebras e aos vencedores cabia a honraria de escolher a mulher que 
desejassem. No Brasil, Pastinha iria reafricanizar a capoeira, tomando por base o mito da dança zebra, que a ligaria à tradição angolana e reafirmaria a raiz africana da luta. Paralelamente, dar-se-ia ênfase à sua inserção em nosso território por intermédio dos escravos provenientes daquela região. ${ }^{4}$ Segundo Vainfas e Mello e Souza (s.d.), "a região do Congo-Angola foi daquelas que mais forneceu africanos para o Brasil, especialmente para o sudeste, posição assumida no século XVII e consolidada na virada do século XVIII para o XIX”. Nesse contexto, Ramos (1979, p. 331) afirma:

Assim, capoeira era uma dança associada aos escravos do sexo masculino que eram versados em seu uso também na luta [...] desenvolvida por angolanos no Brasil, nas fazendas da Bahia durante os séculos XVIII e XIX [...] a música da capoeira mostra uma forte herança angolana, e os capoeiristas estão conscientes da conexão angolana.

Os bantos tinham o hábito da festa, a agilidade de corpo e a destreza; assim, quando os senhores e autoridades se referiam aos movimentos dos negros, quer nas senzalas, nas matas, ou nos dias que lhes eram permitidos, chamavam-lhes “os negros de Angola”. É por isso que, na tentativa de reafirmar os fatos históricos, para Pastinha a capoeira angola é negro-africana.

A capoeira angola possui, então, uma herança africana, que está atrelada ainda ao candomblé. ${ }^{5}$ Essa religiosidade se manifesta, entre outros rituais, na própria entrada da roda, pois o capoeirista angoleiro, antes de fazê-la, se benze tocando o chão, pois o sagrado se materializa no chão da roda, que é o berço da escravidão negra. Isto enfatiza, na capoeira angola, o entrelaçamento de uma imagem africana de vida e de mundo, de princípio e fim, de orum e aiê.

Reis (2000, p. 118-119) argumenta que "a maior pureza na capoeira angola serviu de interesses políticos concernentes aos próprios negros baianos" ao propor uma "origem africana". Sugerimos que esse "interesse político" relacionava-se ao fato de a capoeira regional, vertente da capoeira que se afirma como arte marcial mestiça originária dos terreiros no Brasil, encontrar-se em processo de institucionalização desde os anos 30 do século XX, tendo inclusive sido discriminada por Getúlio Vargas em 1937, e reconhecida ainda por ele em 1953 como esporte genuinamente nacional. Para os "angoleiros", por outro lado, cabia, como temos dito, afirmar a ancestralidade africana e, com isso, distinguir-se de um esporte que era cooptado pelos agentes hegemônicos. 
Assistimos, desse modo, a um processo progressivo de "invenção da tradição” da capoeira angola que se alastraria por todo o país. Neste processo, é necessário resgatar o conceito de tradição inventada proposto por Hobsbawm, como um "conjunto de práticas sociais de natureza ritual ou simbólica que visam inculcar valores e comportamentos por intermédio da repetição, o que implica continuidade em relação a um passado histórico apropriado" (Hobsbawm, 1984, p. 9). Embora esse autor trate de invenção de tradições principalmente pelas classes dominantes, neste ensaio vemos que elas podem ser produzidas também pelas classes subalternas, até mesmo para se diferenciar de outros grupos subalternos: capoeira angola X capoeira regional; capoeira originalmente africana X capoeira da mestiçagem brasileira; capoeira lúdico-religiosa X capoeira arte marcial.

Destarte, a capoeira angola insere o participante no mundo sagrado da tradição religiosa africana segundo o mito fundador daqueles que inventaram seu ideário. Nesta, de acordo com a tradição inventada, o capoeirista busca um poder transcendente e espiritual contido na roda, seja mediante o toque do berimbau, do patuá no pescoço ou das cantigas entoadas que orientam o angoleiro na transcendência. A capoeira angola, além disso, ao contrário da negociação notada em outras manifestações negras, realiza-se como uma manifestação de caráter alternativo na Cidade de Goiás, como veremos a seguir.

\section{Gingando com a territorialidade identitária da capoeira angola na Cidade de Goiás}

Como trataremos de territorialidade, a princípio cumpre destacar que nosso conceito é retirado da obra de Sack, para quem a territorialidade "atravessa fronteiras, símbolos e formas diferentes de combinação direta no espaço, como a mais eficiente estratégia de força de controle e de distribuição no espaço e no tempo" (Sack, 1986, p. 32). Recuperamos esse conceito em razão da necessidade de interpretar socialmente o uso do espaço, relacionando-o com o controle de um território que, neste caso, está repleto de uma enorme carga de sentidos, valores e crenças construídos pelo grupo Meninos de Angola. Segundo Sack (1986, p. 216),

territorialidade é uma expressão geográfica básica de influência e poder, provê uma sociedade essencial de ligação entre tempo e espaço....é o dispositivo geográfico de construção por pessoas de organização no espaço....não é nenhum instinto, mas uma estratégia 
complexa para afetar, influenciar e controlar o acesso de pessoas, coisas, relações e comportamentos.

Na Cidade de Goiás, existe o grupo "Anunciando a Consciência Negra com os Meninos de Angola," que é coordenado pelo aqui denominado Mestre, que desenvolve o trabalho com capoeira angola na periferia da cidade desde 1989. A condição de trabalho em área periférica, aliás, vem ocorrendo com a maioria dos espaços de capoeira angola no Brasil. Neste território, reproduzem-se as insígnias da história dos quilombos, criando em torno de si um círculo subjetivo identitário, uma comunidade de trabalho e um manancial de representação e resistência de arte negra. Destarte, ali a capoeira angola caminha em direção à construção de um olhar sobre o território e sobre o negro, território que se efetiva como instrumento cultural e meio de emancipar-se da ordem política dominante, que subjuga ou nega as manifestações negras numa cidade que, paradoxalmente, dependeu dessa mão de obra para se constituir como arraial de mineração e hoje é considerada pela Unesco como Patrimônio Cultural da Humanidade.

As aulas ministradas pelo Mestre vão além das atividades corporais e físicas, proposta adotada por ele nos fundamentos da capoeira angola. Em entrevista realizada em janeiro de 2005 na Cidade de Goiás, ele revela sua compreensão sobre a capoeira: "É a capoeira educação voltada para a questão da afirmação de uma identidade humana negra de origem negra, que acontece através do diálogo e aprendizado da mística que se reproduz nas aulas e nas rodas" (Sá, 2005). Esclarecemos que esta identidade se concretiza por meio de uma territorialidade, aspecto que foi mencionado anteriormente quando se falou na composição da roda, pois nas aulas aprende-se que a "roda de capoeira" é o palco privilegiado da expressão dos jogadores.

O primeiro passo no aprendizado do "iniciante em angola" é sua relação com o corpo, "sua destreza corporal e principalmente sua mandinga, isto é, sua capacidade de seduzir o adversário, iludi-lo e, se quiser (ou puder), derrotá-lo" (Reis, 2000 p. 200). Neste ponto, faz sentido discordar do termo "adversário", pois efetivamente a ideia da capoeira assenta-se na busca do diálogo para que haja a continuidade não somente da prática mas também de signos pertinentes a essa manifestação. $O$ fato de estabelecer o diálogo não significa que o outro com quem se joga, brinca, dança não seja seu oponente, mas é também aquele com quem se trocam mandingas, bençãos, cantos, ludibriações e, uma vez ou outra, se recebe ou se presenteia com uma rasteira. 
É importante apresentar um pequeno exemplo a respeito da escala da corporeidade no território-da-roda de capoeira angola. $\mathrm{O}$ bom angoleiro, segundo os velhos mestres, é aquele que tem domínio de seu corpo, de sua mente e de seus gestos perante o outro na roda, saindo e entrando nela sem complicações para manter o caráter ritualístico do jogo. Assim, como observa Maia (2010, p. 110), ao tratar dos rituais, na roda, 'os direcionamentos e posicionamentos espaciais, que se tornam gestos, danças, performances, enfim movimentos são mais importantes que as palavras, e o desejo de regras mais necessário do que sua execução". Além disso, é na "roda de Angola" que a pessoa mostra se está preparada ou não para a "roda da vida". Por isso, o angoleiro tem de saber respeitar o tempo de iniciação do outro com quem divide o espaço interno da roda. Existe uma diferença entre assistir à capoeira angola e participar dela. Não é possível compreendê-la, tampouco perceber seus múltiplos diálogos, sem tomar parte. A respeito do debate corporal, concordamos com Tavares (1984, p. 103), quando este afirma:

Ludicidade e festividade são formas de entrelaçamento que pressupõem este aspecto: afetividade integradora no processo comunitário. E, na trama das inter-relações da comunidade, o corpo de cada agente é parte integradora da grande rede energética para a resistência. O corpo é integrado no mundo. O corpo é síntese e texto desse processo eu-vida-mundo-consciência.

Em conjunto com o corpo, devem ser acrescentados a linguagem da música e dos gestos, o sentimento e a emoção. Todas essas formas de manifestações tornam-se signos ritualísticos, substanciados no corpo que exprime na roda de Angola a identidade das atividades simbólicas de representação e significação do mundo. A composição dessas atividades revela um conjunto linguístico próprio desse corpo. O corpo que, sob inúmeras formas, foi mutilado na capoeira angola, tem a possibilidade do controle e utilização de seus membros no gingado, na dança e no canto que usou para formar e criar identidades próprias do angoleiro como tal. Então, por intermédio de mudanças de âmbito social, político e religioso essas identidades são celebradas em rituais com práticas corporais.

Este grupo da Cidade de Goiás em particular possui fortes elos de ligação com a casa de candomblé Iê Axé Ibá Ibomim, conhecida popularmente como a Casa do Pai João de Oxóssi. Os eventos ligados à cultura negra nessa casa fazem parte do laço territorial estabelecido entre o grupo 
Meninos de Angola e outro denominado Calunga. Não por acaso, os mestres desses grupos costumam relacionar os aprendizados da capoeira aos do povo-de-santo. De modo semelhante ao que já foi anunciado por Bastide (2001) quando este adverte sobre o candomblé, a capoeira angola é um mundo onde o tempo não pertence somente a um angoleiro, mas ao conjunto do grupo, onde a iniciação acontece aos poucos, em conjunto e com os demais, feita pelo mestre que os direcionam. Assim acontece nas rodas de Angola: cada instrumento tem um segredo ao ser tocado ou manuseado. Seu uso é feito por aqueles que têm domínio ou já foram iniciados. A execução dos instrumentos depende do grau de iniciação dos angoleiros e não basta saber tocá-los, mas é imprescindível estar em sintonia consigo, com o grupo e com o lugar onde acontece a roda. Por exemplo, o berimbau gunga só é tangido pelo Mestre ou por um aluno de sua confiança, geralmente o mais experiente do grupo. Por outro lado, comumente o primeiro instrumento que se aprende a tocar na roda de capoeira angola é o reco-reco, vindo em seguida o agogô, o pandeiro, o atabaque e, por fim, os berimbaus viola - médio e gunga - que traduzem diferentes graus de iniciação e disposição corporal no território da roda.

Entre os ensinamentos da capoeira angola aprende-se que a roda de Angola, em sua perspectiva religiosa, não difere da roda da vida no senso comum, como atestam os mestres, porque ela se move juntamente com as realidades da vida cotidiana. A representação de certo credo relacionado à religiosidade africana soa no sentido real das atividades simbólicas que são devotadas, produzidas e intensificadas pelos angoleiros e pelos seus mestres. Essas atividades simbólicas do sistema cultural da roda são de tal modo invioláveis que, quebrar o ritual, é como faltar a uma ação religiosa negra ligada a convicções sagradas.

Como regra, na capoeira angola o rito é esse elemento que possibilita ao corpo mostrar-se em sua existência sagrada na roda. No seu interior, para que o ritual se perpetue, não há outro caminho senão a mandinga, o corpo fechado, a reverência aos orixás. Ocorrem, com efeito, no território da roda, ritos mágicos com suas principais características de intervenção e emoção repassados pela tradição oral (Maia, 2010). Nesse sentido, a roda revive no espaço mundano a natureza "não letrada", no que se refere à transmissão de conhecimentos dos povos africanos, transmissão que se dava de forma oral, ${ }^{6}$ como mostra Bastide (2001).

Cabe complementar a base teórica para a discussão feita neste ensaio com a definição de território apresentada por Raffestin (1983, p. 79), 
que o toma como "um trunfo particular, recurso e entrave, continente e conteúdo, tudo ao mesmo tempo. O território é o espaço político por excelência, o campo de ação" dos seus atores sociais. É assim que os atores de certo território têm necessidade de uma profundidade espacial, isto é, de construir em torno de si uma área de segurança. Na roda, estes elementos estão presentes na música (canto e toque), na dança e na religiosidade da capoeira angola.

Nosso trabalho de pesquisa-ação junto ao grupo concretizou-se por meio de um trabalho de campo em que pudemos vivenciar a roda em um público diferenciado de jovens, adultos e crianças. Os alunos que se dirigem para o "Espaço Pluri", 7 onde se envolvem com a capoeira angola, em sua maioria possuem traços dos diferentes pontos territoriais do patrimônio "esquecido pela humanidade". ${ }^{8}$

Neste momento, cabe introduzir um pouco em nossa discussão a questão da identidade e, a esse respeito, encontramos na obra de um historiador baiano o seguinte comentário: "Os escravos africanos fizeram de muitos aspectos de seu passado um instrumento de identidade coletiva e transformação social” (Reis, 2003, p. 311), fato que, até hoje, alimenta e orienta a autoimagem do capoeirista em vários sentidos. Não se pode, inclusive, relegar a segundo plano o dado de que a identidade brasileira esteja associada à relação dos africanos com nosso cotidiano nos gostos, gestos, palavras, músicas, festas, culinárias e relações pessoais.

Para nós, a identidade pode então ser tida como "o processo de construção de significado com base em atributo cultural, ou ainda um conjunto de atributos culturais inter-relacionados, o(s) qual(ais) prevalecem sobre outra fonte de significado" (Castels, 1999, p. 22). No caso de nosso "objeto" de análise, a identidade é construída na relação dos angoleiros com a pluralidade de atributos culturais da Cidade de Goiás. É desses atributos que os angoleiros intencionalmente recuperam os aspectos constitutivos da ancestralidade e da religiosidade africana, fundamentando as relações intersubjetivas da capoeira angola e demais manifestações negras dessa cidade como o Afoxé Aiyó Delê, o Espaço Educativo Vila Esperança, a Escola Quilombinho, ou os terreiros religiosos. É desse modo que a capoeira angola revela uma identidade de resistência, carregando consigo, na versão dos atores que a praticam, feições de expressão, educação, companheirismo, respeito, religiosidade e afetividade do africano, posto que a identidade de resistência é 
criada por atores que se encontram em posições/condições desvalorizadas e/ou estigmatizadas pela lógica de dominação, construindo assim, trincheiras de resistência e sobrevivência com base em princípios diferentes dos que permeiam as instituições da sociedade. (Castells, 1999, p. 24)

Isto ratifica a postura do grupo ao identificar-se como negro na sociedade vilaboense, ao mesmo tempo em que se diferencia de "outros". Neste contexto relacional em que está envolvido, o grupo pesquisado assume a "negritude" e a "africanidade" como construções simbólicas, já que muitos são pardos e nenhum deles africano; mas isto serve para combater a suposta inferioridade e outros valores negativos inculcados pelos colonizadores e ainda vigentes não apenas na sociedade vilaboense.

\section{Canto de Angola na Cidade de Goiás}

Não se pode negar a importância do canto como meio de formação da identidade e demarcação da territorialidade no grupo estudado, o que se traduz, essencialmente, nos elos existentes entre a capoeira angola e o candomblé. Tal como ocorre no candomblé, o cântico da capoeira é dançado e, como dissemos, promove transcendência. Mas paralelamente o canto é também uma linguagem, sendo esta "um instrumento de poder da mesma forma que qualquer outro; não que possa ser o objeto de uma apropriação privada, mas pode ser manipulada, com mais ou menos eficácia” (Raffestin, 1993, p. 107). Neste caso, a linguagem do canto da capoeira angola serviu e serve como modo de expressão daqueles que se rebelam contra imposições, mantendo vivos seus hábitos, tradições, valores, costumes, ações no território e identidade. Reforçamos nossa consideração a respeito da escravatura a partir do que afirma Reis, para quem "os escravos fizeram de muitos aspectos de seu passado um instrumento de identidade coletiva e transformação social” (Reis, 2003, p. 311). É por isso que nos remetemos aos cantos da capoeira angola como configuração simbólica e de crenças relacionadas à vida de negros e brancos.

Os cânticos da capoeira angola recebem a denominação de ladainhas, chulas e corridos, sendo altamente significativos para os angoleiros. Os cantos são compostos por orações e rezas formadas por uma série de invocações curtas e respostas repetidas, relacionadas a rituais angoleiros. As ladainhas são pequenas cantigas em que se faz uma oração pedindo proteção no momento da roda, podendo ser um desafio àquele com quem 
se joga, a narração de um fato, de um acontecimento da vida dos capoeiristas ou outro fato especial. A ladainha faz parte do repertório da capoeira angola e é assim chamada o canto executado por uma pessoa que entoa a música completa, enquanto os demais cantam, em coro, o refrão. Na capoeira angola, a música é tão fundamental quanto a dança. Assim como no candomblé, ela acontece por ocasião do encontro, da festa, como comemoração a mais um dia, ou pelo gosto de cantar e fazer bailar os quadris no território sagrado. Na roda, a possessão acontece como rito de brincadeira, como forma de vida alegre e "retorno" a um passado que foi arrancado e agora é reafirmado.

Também temos o caso dos corridos, que são, igualmente, cantigas de louvação, aviso ou agradecimento, cantadas em pequenas quadras com a participação do coro. No momento da roda, o corrido torna-se uma cantiga de aviso aos dois angoleiros que vão se encontrar no interior do espaço. A título de ilustração, citamos dois corridos. Um deles diz:

Ó Santa Bárbara do relampuê

É Santa Bárbara do relampuá

Ó Santa Bárbara do relampuê

Do relampuê do relampuá

Do relampuê do relampuá.

Nesse corrido, Santa Bárbara é identificada com Iansã ${ }^{9}$ por alguns estudiosos da religião iorubá. Segundo Pierre Verger (2002, p. 26), Iansã está "ligada à tempestade e aos relâmpagos e foi identificada como Santa Bárbara. Reza a lenda que o pai dessa santa sacrificou-a devido a sua conversão ao cristianismo [...] em seguida foi atingido por raio e reduzido a cinzas". Acrescentamos outro exemplo de um corrido popular entoado pelo grupo Meninos de Angola:

Ê, ô, ê, Iganga

Vamos louvar sarabanda ${ }^{10}$

Ô, Iganga, ê, ô, ê, Iganga

Vamos louvar sarabanda

Ô Iganga, vamos louvar sarabanda

Ô Iganga, vamos louvar sarabanda

Ô Iganga, vamos louvar sarabanda

Ô Iganga. 
Mas existem também as chulas, que são igualmente cantigas de louvação, aviso ou agradecimentos, mas cantadas no momento em que aquele que está comandando o canto dá um sinal para a participação do coro.

Além da capoeira, com suas linguagens, religiosidade, ancestralidade, territorialidade e identidade temos ainda entre os angoleiros do grupo pesquisado na Cidade de Goiás as festividades como fato social marcante. Quanto a isto, destaque-se que "o calendário africano foi inserido no calendário português, ou se adaptou a ele. Assim o branco não viu nada de mal no que faziam os negros de sua propriedade, e esses podiam manter sem nenhum risco as cerimônias ancestrais” (Bastide, 2001, p. 89). Para o grupo Meninos de Angola, cada dia da semana possui uma referência a ser celebrada, já que todo dia é dia de santo. Porém, em cada mês, escolhe-se um dia a ser festejado. As tarefas se dividem entre "meninas e meninos", como diz o Mestre, levando em consideração que a faixa etária varia de oito a trinta anos. Nessas celebrações, frutas, doces, tortas, flores, vinho, sucos, pratos, talheres, copos e outros utensílios são reunidos no espaço do grupo para a comemoração acompanhada de muita música e devoção.

As festas e as atividades desenvolvidas pelo grupo na comunidade vilaboense fazem com que ela seja reconhecida como um território alternativo, uma vez que a referência negra é valorizada por esta comunidade, o que a torna um "espaço diferenciado" na sua proposta de projeto. Haesbaert utiliza a expressão alternativo

no sentido da crítica aos espaços hegemônicos, que se alia a uma esperança por uma "alternativa” que permita a construção de um espaço muito mais igualitário e democrático onde se dê a inserção dos excluídos e de todas as matizes, alternativos no sentido de novas perspectivas teóricas para analisar o espaço dos homens que superem a dicotomia entre sensibilidade e razão, experiência e representação. (Haesbaert, 2002, p. 11)

Com as festas, o grupo Meninos de Angola reafirma a importância de uma identidade construída em seu território de forma viva e dinâmica, enquanto que nas instituições vilaboenses que se preocupam com a preservação da memória, a identidade do negro é tratada como fotografia de um passado distante, ou seja, atores coadjuvantes na história e na geografia da cidade. Isso faz com que a sua importância e representação construídas no interior do grupo se contraponham àquela apregoada pela ordem dominante na cidade, onde se nota a valorização simbólica de ícones ligados à colonização e relacionados à figura dos bandeirantes, como a Cruz 
do Anhanguera. Desse modo, a partir da capoeira, outros leques se abrem para falar das maneiras que o grupo possui de se manifestar mediante suas articulações territoriais de resistência, que são humanas e artísticas, em contraposição aos espaços massificadores impostos pela ordem social e política na Cidade de Goiás. Oxalá outros se aventurem nesta bandeira de desbravamento da condição no negro nesta cidade, que é Patrimônio Histórico da Humanidade.

\section{Conclusão}

Entendemos que o grupo Meninos de Angola constroi uma territorialidade ímpar na Cidade de Goiás por meio dos trabalhos desenvolvidos com as crianças, adolescentes, jovens e adultos. Ao mesmo tempo, a construção da territorialidade implica na representação daqueles que a compõem. Considerando a possibilidade de exequibilidade dessa pesquisa, acreditamos que ela contribua de fato para o conhecimento teórico e prático da realidade do estado da arte negra na Cidade de Goiás. Utilizando o aporte conceitual desenvolvido pela geografia humana e demais ciências humanas, entendemos que os estudos feitos nos orientam nesta discussão, embora alguns conceitos precisem ser ampliados em face da realidade complexa que encontramos no grupo estudado. Portanto, vale-nos persistir no interesse por tal caminho, ainda a ser construído, tomando como norte reflexivo o projeto do grupo "Associação Anunciando a Consciência Negra com os Meninos de Angola”.

\section{Notas}

1 A arte negra da capoeira foi estabelecida pelo trabalho de Vicente Ferreira Pastinha, que retomou seu caráter "negro", agora denominando-a oficialmente de Capoeira Angola. Pastinha, como é conhecido, empenhou-se na sua legitimação, firmando uma maior proximidade com a África a partir de elos com a religião e a ancestralidade africanas. Ele objetivou reafricanizar a prática da capoeira, criando um mito de origem que a ligaria a uma Angola mística. Destarte entramos num mundo sagrado em que o capoeirista busca poderes transcendentais e espirituais contidos nas rodas da capoeira angola, seja no pé do berimbau, no patuá no pescoço, nas cantigas entoadas e até mesmo na orquestra ao seu lado, que é base de seus fundamentos.

2 Nome dado ao "professor" de capoeira que na Angola era mais do que professor, significando orientador, mentor, alguém que precisa de entender os múltiplos sentidos da arte, filosofia e religião de origem africana expressos na capoeira Angola. 
3 Juntamente com João Grande, João Pequeno e Curió, Moraes é um dos principais responsáveis por manter viva a Capoeira Angola no Brasil.

4 De acordo com Arthur Ramos (1979, p. 225), os negros bantos são responsáveis pela sobrevivência de várias manifestações culturais, entre elas o congo, o kibungo, os cucumbis e a capoeira.

5 Consideramos importante recuperar o pensamento de Roger Bastide, que buscou compreender o universo da religiosidade afro-brasileira de modo profundo. De acordo com esse autor, o mundo dos candomblés é um mundo secreto, onde só se entra pouco a pouco e essa entrada "efetua-se por meio de uma série de iniciações progressivas de cerimônias especializadas [...] e é à medida que se vai penetrando no interior do santuário que os mistérios vão sendo aprendidos" (Bastide, 2001, p. 25).

6 Fazemos, neste ponto, um elo de ligação com Bastide (2001, p. 36), para quem "os cânticos [...] não são apenas cantados, são também 'dançados', pois constituem a evocação de certos episódios da história dos deuses”. Os corpos dos capoeiristas, em forma de gesto e dança, festejam, cantam e dançam uma conquista histórica que pode apresentar os traços de uma manifestação que foi perseguida.

7 O Espaço Pluri pertence ao Mosteiro Beneditino de Taunay na Cidade de Goiás. Seu representante apoia a arte negra e cede o espaço para que o Mestre desenvolva ali a capoeira Angola. É importante ressaltar que o Espaço Pluri possui ligação com o terreiro de Mãe Estela, o Axé Apo Afonjá, em Salvador.

8 Como mostramos anteriormente, a Cidade de Goiás recebeu no ano de 2001 o título de Patrimônio Histórico da Humanidade.

9 Segundo Bastide (2001, p. 102), Iansã preside às tempestades, à chuva torrencial, aos vendavais.

10 Em Bastide (1974, p. 106), "Sarabanda ou zarabanda é uma magia nascida em Havana, do sincretismo entre a cultura ioruba e a congo, pois zarabanda é considerada como o equivalente congo do deus ioruba da guerra, Ogum, cuja oração se põe dentro do recipiente com outros ingredientes, ossos não obrigatoriamente humanos e plantas do mato".

\section{Referências}

BASTIDE, Roger. O candomblé na Bahia: rito Nagô. São Paulo: Companhia das Letras, 2001. 370p.

BASTIDE, Roger. As américas negras: as civilizações africanas no Novo Mundo. São Paulo: Ed. da USP, 1974. 210p.

CASTELLS, Manuel. O poder da identidade. São Paulo: Paz e Terra, 1999. 530p.

HAESBAERT, Rogério. Territórios alternativos. Niterói: Eduff; São Paulo: Contexto, 2002. 186p.

HOBSBAWM, Eric. Introdução: a invenção das tradições. In: .; RANGER, Terence (Orgs.). A invenção das tradições. Rio de Janeiro: Paz e Terra, 1984. p. 9-24. 
MAIA, Carlos Eduardo Santos. Ritual e emoção nas interações espaciais: repensando o sagrado nas festas populares de romarias e folguedos. In: ROSENDAHL, Zeny. Trilhas do sagrado. Rio de Janeiro: Eduerj, 2010. p. 87-111.

RAFFESTIN, Claude. Por uma geografia do poder. São Paulo: Ática, 1993. 269p.

RAMOS, Arthur. As culturas negras no Novo Mundo. Rio de Janeiro: Editora Nacional, 1979. 399p.

REIS, Letícia Vidor S. O mundo de pernas para o ar: a capoeira no Brasil. São Paulo: Publisher, 2000. 207p.

REIS. João José. Rebelião escrava no Brasil: a história dos levantes dos malês em 1835. São Paulo: Companhia das Letras, 2003. 293p.

SACK, R. Human territorialy: its theory and history. Cambridge: Cambridge University Press, 1986. 256p.

TAVARES, Julio César. Dança da guerra: arquivo-arma. Brasília. 1984. 152p. Dissertação (Mestrado em Sociologia) - Departamento de Sociologia, Universidade de Brasília.

VAINFAS, R.; MELLO E SOUZA, M. de. Catolização e poder no tráfico: o reino do Congo da conversão coroada ao movimento antoniano, séculos XV-XVIII. Disponível em: http://www.historia.uff.br/tempo/artigos_dossie/artg6-7.pdf. Acesso em: 28/5/2010.

VERGER, Pierre Fatumbi. Orixás deuses iorubás na África no Novo Mundo. Salvador: Corrupio, 2002. 295p.

\section{Entrevista}

Entrevista realizada em janeiro de 2005 com Estevan de Sá, conhecido comumente como Chuluca, de 33 anos, residente na Cidade de Goiás, mestre de capoeira e fundador do grupo "Anunciando a Consciência Negra com os Meninos de Angola”.

Rosemberg Ferracini - Doutorando em Geografia pela Universidade de São Paulo.

Carlos Eduardo Santos Maia - Professor Adjunto da Universidade Federal de Juiz de Fora.

Recebido para publicação em abril de 2010

Aceito para publicação em junho de 2010 